\title{
Estratégias de educação sustentável e gestão de pessoas: novos rumos?
}

\section{Resumo}

Neste artigo buscou-se compreender se as Instituições de Ensino Superior (IES), nos cursos de Administração que priorizam a educação sustentável de modo compatível aos Principles for Responsible Management Education (PRME), tornaram seus alunos candidatos potenciais nos processos de recrutamento e seleção em empresas brasileiras. A base teórica alicerçou-se em Boyatzis e Dutra. A metodologia é de caráter exploratório - descritiva com abordagem qualitativa. Os resultados demonstram que a maioria das empresas, apesar de considerarem fundamental o conhecimento dos candidatos sobre educação sustentável, ainda não utiliza esse critério nos processos de recrutamento, seleção e desenvolvimento de carreira, em virtude do desconhecimento em relação ao esforço que as IES vêm realizando juntamente à rede PRME.

Palavras-chave: Educação Sustentável, Gestão de Pessoas, Principles for Responsible Management Education (PRME)

\section{Strategy of sustainable education and people management: new directions?}

\section{Abstract}

The aim of this article is to understand if Institutions of Higher Education from Management courses focused on sustainable education in a compatible approach to the Principles for Responsible Management Education (PRME), are developing their students to be potential candidates in the recruitment and selection processes in the Brazilian Companies. The theoretical content is based on Boyatzis and Dutra. The methodology is an exploratory and descriptive with a qualitative and quantitative approach. The results demonstrated that the majority of the companies consider knowledge on sustainable education fundamental but these companies admit that they still don't consider this topic during the recruitment, selection and career development due to the lack of measurement of efforts made by the Institutions of Higher Education in partnership with the PRME.

Keywords: Sustainable education, Management of People, Principles for Responsible Management Education (PRME).

\footnotetext{
Doutoranda em Administração de Empresas pela USCS Professora Universitária USCS-Universidade Municipal de São Caetano do Sul Campus II - Rua Santo Antônio, 50 - CEP. 09521-160 - São Caetano do Sul - SP 4239-3354 (Marlene) Área Gestão de Pessoas. email: dartisoares@terra.com.br.

2 Prof.Dr.Programa PPGA USCS-Universidade Municipal de São Caetano do Sul. Área Gestão de Pessoas. email: eduardo.oliva@uscs.edu.br

${ }^{3}$ Doutoranda em Administração pela USCS-Universidade Municipal de São Caetano do Sul. Professora do Departamento de Ciências Gerenciais da UNINOVE.email: alba.zucco@gmail.com
} 


\section{Introd ução}

As transformações ocorridas no cenário do ensino superior no Brasil, nas últimas décadas, trouxeram uma série de mudanças estruturais e consequentes desafios para as IES - Instituições de Ensino Superior. A oferta de novos cursos, o aumento do número de vagas e a dimensão das práticas pedagógicas nas salas de aulas são alguns dos projetos voltados para a sustentabilidade do planeta, principalmente se for levada em conta a preocupação com as gerações futuras. (SILVA, 2009).

O desafio dos cursos de administração das IES em relação à preparação dos jovens para o mercado de trabalho torna-se uma questão relevante nesta conjuntura, visto que com as tecnologias se renovando em períodos cada vez menores e a concorrência entre empresas cada vez maiores, há a preocupação constante de uma produção de melhor qualidade, sustentabilidade e eficácia dos processos nas organizações.

Nessa perspectiva, existe a necessidade de preparar novos gestores, pois a busca desses objetivos, entre qualidade, sustentabilidade e competitividade, passa obrigatoriamente pela educação. E, em decorrência de uma sociedade emergente, manifestada por meio de avanços tecnológicos e dos desdobramentos dos novos gestores nas questões do meio ambiente, algumas IES procuram adequar suas grades curriculares numa educação sustentável, as quais permitam experiências eficazes de aprendizagem para a liderança responsável (SILVA, 2011).

Para nortear as Instituições de Ensino Superior (IES) no que diz respeito às inovações requeridas por esse novo contexto, em 2007, sob a coordenação do Pacto Global da Organização das Nações Unidas (ONU) e das principais instituições acadêmicas, representadas por 60 reitores, presidentes de universidades e representantes oficiais das principais escolas de negócios e instituições acadêmicas, foram instituídos os Princípios de Educação Responsável em Gestão - PRME, que englobam um conjunto de seis princípios que estabelecem a base de uma plataforma global para a educação de gestão responsável.

Gadotti (2007) relata que, para responder à complexidade da sociedade contemporânea, a construção de uma sociedade sustentável tem um componente educativo, pois a formação de uma consciência ecológica depende da educação para se cultivar uma vida sustentável. Do contrário, o planeta continuará sendo percebido apenas como um instrumento para garantir um modo de vida predatório.

Silva (2011) confirma que a sustentabilidade pode oferecer um futuro às empresas. Possivelmente, uma das características mais marcantes das empresas é o fato de que elas conseguem ter uma visão no longo prazo. Consequentemente, o administrador teria o desafio de entender esse aspecto e projetar tendências futuras, traçar e operacionalizar estratégias de sobrevivência, alocando da forma mais eficiente possível os recursos que estão à disposição.

Por conseguinte, à medida que as empresas incorporarem nas suas estratégias a dimensão gestão responsável, o envolvimento e a ação da área de Gestão de Pessoas se tornarão essenciais, pois se valerão de seu posicionamento central na organização para impulsionar a ação pela sustentabilidade socioambiental (PEREIRA, 2013).

Diante disso, a área de Gestão de Pessoas, a fim de garantir o nível de competitividade atual e o futuro da organização, estabelece uma estratégia no processo de recrutamento e seleção para atrair profissionais competentes, não só em questões técnicas, mas também comprometidos com a interiorização da dimensão ambiental. Além disso, uma atenção maior à questão de sustentabilidade poderia contribuir com os objetivos organizacionais e também com a carreira dos candidatos (DURANT, 2000).

Especificamente, a pesquisa advém do ambiente em que as IES estão inseridas versus sua habilidade de responder às necessidades decorrentes das novas exigências para uma 
educação responsável em gestão.

Com tais considerações, o objetivo desta pesquisa é verificar se as IES que utilizam os PRME possibilitam aos alunos se tornarem candidatos potenciais nos processos de recrutamento e seleção em empresas brasileiras.

\section{Educação Sustentável}

Todas as mudanças significativas na história começam nas mentes, nos sonhos e na consciência das pessoas. Ações eficazes, novos pensamentos e novos níveis de consciência podem mudar a sociedade, colocando-nos na direção e caminho certos (BOFF, 2012).

Segundo Silva (2011), somente uma boa educação, como meio de transformação social, tem a capacidade de formar cidadãos inteligentes e articulados em todos os sentidos. Isso significa dizer que todo modelo de formação, capacitação, educação, treinamento ou desenvolvimento deve assegurar ao ser humano a oportunidade de ser o que pode ser com base em suas próprias potencialidades, sejam elas inatas ou adquiridas.

Vale lembrar que a educação vem sendo repensada como uma preparação para a vida, garantindo, além da segurança do emprego e aptidão para o trabalho, uma maneira de encarar os recursos naturais e sustentáveis como indispensáveis à sobrevivência humana (SACHS, 1996).

Veiga (2006) corrobora com os demais autores buscando discutir as novas questões que devem permear a formação de futuros gestores, ressaltando que as IES - Instituições de Ensino Superior poderiam criar caminhos e alternativas nos quais a questão de educação sustentável se configure tendo um papel fundamental em sala de aula. Para tanto, recomendase educar e treinar os futuros tomadores de decisão, para que eles adquiram os valores, competências, habilidades e conhecimentos que lhes possibilitem contribuir com a construção de uma sociedade mais sustentável.

Tal exigência se deve ao fato de que, no mercado de trabalho, algumas empresas, em busca de talentos, projetos e ideias, se esquecem de como os processos produtivos sem padrões de sustentabilidade acabam, de diversas formas, destruindo a natureza, poluindo a hidrografia, prejudicando seres vivos e modificando a superfície global, trazendo como resultado as catástrofes naturais que culminam por atingir as próprias empresas (SILVA, 2011).

Desse modo, o mercado requer dos atuais gestores uma formação profissional adequada à realidade, bem como o compromisso socioambiental e desenvolvimento pleno das competências e habilidades cognitivas socioculturais, que propiciem sua inserção e permanência no mercado de trabalho. E, de acordo com Veloso (2009), o senso comum prediz que os gestores deveriam assumir um papel ativo no planejamento da própria carreira.

Tal postura implica em que as IES revejam os conteúdos de ensino para responder aos desafios ambientais, promovendo métodos de ensino que permitam aos estudantes adquirirem habilidades, tais como: pensamento interdisciplinar, planejamento integrado, complexidade da compreensão, cooperação em processos de decisão e participação em processos locais, nacionais e globais para o desenvolvimento sustentável (GADOTTI, 2007). De acordo com Sana (2006), sabe-se que, por um lado, não é possível atribuir à escola e a seus profissionais a responsabilidade pela transformação do ser humano e, por outro, se acredita em sua contribuição para a conclusão desse objetivo. O ideal é que as escolas sejam capazes de formar uma nova geração de líderes que estejam preparados para enfrentar os desafios complexos que o século XXI tem exigido das empresas e da sociedade (ROEDEL, 2012).

No entanto, formar profissionais capazes em lidar com as adversidades com as quais convivem, representa para as IES um considerável desafio, porquanto seja preciso prospectar uma visão de ensino em relação às empresas que, por sua vez, são moldadas pelas práticas 
de desenvolvimento tecnológico, cultural e econômico. Nesta linha, torna-se indispensável para a formação do profissional as IES considerarem, nas salas de aulas, alternativas que assegurem a sobrevivência dos alunos no mercado de trabalho (SILVA, 2011).

Por mais de uma década, muitas IES, organizações não governamentais e agências de governo do mundo inteiro fizeram esforços significativos para incorporar o desenvolvimento sustentável em programas acadêmicos. Segundo Silva (2011), a educação deve fazer parte da pauta de discussões dos governantes sobre sustentabilidade, pois é uma nova maneira de encarar os problemas ambientais, que acabam refletindo no mercado de trabalho.

Diante disso, por ocasião da Conferência das Nações Unidas sobre Desenvolvimento Sustentável, em 2012, na cidade do Rio de Janeiro, ou Rio +20 , os líderes da comunidade acadêmica internacional foram solicitados a se empenharem no desenvolvimento de práticas sustentáveis para as IES (UNESCO, 2012).

Desse modo, 260 universidades de todo o mundo aprovaram uma Declaração para Instituições de Ensino Superior, com o compromisso de inserção do tema sustentabilidade no cerne de suas faculdades e dos currículos universitários, além de incorporarem, em suas próprias gestões, atividades organizacionais em benefício das gerações presentes e futuras (ONU, 2012). A iniciativa foi convocada pela agência da ONU para a Educação, Ciência e Cultura (UNESCO), pela Universidade das Nações Unidas, pelo Pacto Global, com apoio dos Princípios para a Gestão da Educação Responsável das Nações Unidas (PRME) e do Programa Ambiental das Nações Unidas (UNEP).

O Quadro 1 demonstra os objetivos propostos para as novas Iniciativas de Educação Superior para o Desenvolvimento Sustentável (ONU, 2012), com as respectivas práticas.

Quadro 1 - Iniciativas da Educação Superior para o Desenvolvimento Sustentável

\begin{abstract}
Ensinar conceitos de desenv olvimento sustentável
Garantir que eles façam parte do currículo básico em todas as disciplinas para que os futuros diplomados do ensino superior desenvolvam habilidades necessárias ao desenvolvimento sustentável e tenham um entendimento explícito de como alcançar uma sociedade que valoriza as pessoas, o planeta e os lucros de uma maneir a que respeitem os limites de recursos. Instituições de Ensino Superior também são encorạj adas a proporcionarem formação em sustentabilidade para os profissionais e funcionários

Incen tivar a investigação sobre questões de desenv olvimento sustentável

Melhorar a compreensão científica por meio do intercâmbio de conhecimentos científicos e tecnológicos, intensificando o desenvolvimento, adaptação, difusão e transferência de conhecimentos incluindo tecnologias inovadoras.
\end{abstract}

Apoiar os esforços de sustentabilidade nas comunidades
Trabalhando com as autoridades locais e a sociedade civil, tornando-as mais habitáveis e eco eficientes,
socialmente inchusivas e com baixo vestígio ambiental.

Compr ometer com o compartilhamen to de resultados e ações

Por meio de quadros internacionais, como a Década das Nações Unidas da Educação para o De senvolvimento.

Fonte: ONU (2012).

É válido, ainda, considerar uma mudança de paradigmas, pela qual poderão se formar não apenas profissionais multifuncionais, mas cidadãos responsáveis que, mediante experiência dentro de uma IES, replicarão esse aprendizado nas organizações e nos diversos setores de suas vidas (DEA JUNIOR, ROSA e SAMPAIO, 2010; BARBOSA, 2002). 


\section{Os Princípios de Educação Responsável em Gestão (PRME)}

O PRME foi desenvolvido, em 2007, por uma organização internacional força-tarefa, constituída por 60 reitores, presidentes de universidades e representantes oficiais das principais escolas de negócios e instituições acadêmicas.

A ideia de desenvolver um princípio-plataforma baseado no engajamento global para instituições acadêmicas decorreu de uma recomendação de todos os atores acadêmicos do Pacto Global da ONU. Foi apresentada oficialmente pelo Escritório do Pacto Global no Fórum Global "Negócios como Agente de Benefício do Mundo" da Case Western Reserve University, em outubro de 2006.

As instituições acadêmicas mencionadas a seguir foram convocadas para elaborar o referido documento em conjunto com o Pacto Global da ONU, que, mais tarde, aprovou o documento final: (i) AACSB International (Association to Advance Collegiate Schools of Business); (ii) Fundação Europeia para a Gestão de Desenvolvimento (EFMD); (iii) O Aspen Business Institute e Sociedade; (iv) Academia Europeia de Empresas na Sociedade (EABIS); (v) Iniciativa de Liderança Globalmente Responsável (GRLI) e (vi) Net Impact.

A rede PRME pode servir como um marco para a mudança sistêmica das escolas de negócios e instituições relacionados com a gestão, com base em três características que distinguem a iniciativa:

1- Melhoria Contínua: qualquer escola que está disposta a se envolver e implementar os princípios do PRME deve fazê-lo em condições que engajem professores e funcionários na construção deste futuro.

2- Uma rede de aprendizagem: a iniciativa PRME também funciona como uma rede de aprendizagem, por meio da coleta e da canalização de boas práticas, que vão facilitar a troca de experiências existentes e estado da arte dentro da rede PRME.

3- Relatório de Stakeholders: adotar o PRME implica que a escola signatária esteja disposta a informar regularmente - anualmente - seu progresso para todos os stakeholders. Comunicação pública é a melhor maneira de garantir a credibilidade da iniciativa, além de permitir que se dê reconhecimento às boas performances.

Assim, voluntariamente, reconhecendo que estão envolvidas no desenvolvimento de atuais e futuros gestores, as IES declaram-se dispostas a avançar na implementação do PRME, por meio dos princípios mencionados no Quadro 2, a começar por aqueles que são mais relevantes.

\section{Quadro 2 - Os 6 princípios}

Princípio 1 | Objetivo: Desenvolver as capacidades dos estudantes para serem futuros geradores de valor sustentável para as empresas e a sociedade em geral e trabalhar para uma economia global, indusiva e sustentável.

Princípio 2 | Valores: Incorporar em nossas atividades acadêmicas e currículos os valores da responsabilidade social global como retratado em iniciativas intemacionais, como o Pacto Global das Nações Unidas.

Princípio 3 | Método: Criar estruturas pedagógicas, materiais, processos e ambientes que permitam experiências eficazes de aprendizagem para a liderança responsável.

Princípio 4 | Pesquisa: Participar de pesquisas conceituais e empíticas que possibilitarão avançar nossa compreensão sobre o papel, dinâmica e impacto das corporações na criação de valores sustentáveis: social, ambiental e econômico.

Princípio 5 | Parceria: Interagir com gerentes de empresas de negócios para ampliar nosso conhe cimetto sobre seus desafios no cumprimento de responsabilidades sociais e ambientais e explorar conjuntamente abordagens eficientes para enfrentar esses desafios.

Princípio 6 | Diálogo: Facilitar e apoiar o diálogo e o debate entre educadores, estudantes, empresas governos, consumidores, mídia, organizações da sociedade civil e outros grupos interessados em refletirem a respeito das questões críticas relacionadas à responsabilidade social global e sustentabilidade. 
Do mesmo modo, a rede PRME entende que as práticas organizacionais devam servir como exemplo dos valores e atitudes que serão transmitidos aos alunos (PRME, 2012).

A seguir, na Tabela 1, demonstra-se como se distribuiu a implementação dos princípios no mundo das instituições de ensino superior que se inscreveram para a iniciativa dos PRME, 482 IES no total.

Tabela 1 - Implementação dos princípios no Mundo

\begin{tabular}{|l|l|}
\hline$\%$ & País \\
\hline $35 \%$ & Europa Ocidental \\
\hline $25 \%$ & América do Norte \\
\hline $11 \%$ & Ásia \\
\hline $11 \%$ & América Latina \\
\hline $9 \%$ & Europa Oriental \\
\hline $6 \%$ & Oriente Médio e África \\
\hline $3 \%$ & Austrália \\
\hline
\end{tabular}

Fonte: http://www.unprme.org/index, 2012.

Importa esclarecer que adotar os $P R M E$ pressupõe que um participante esteja disposto a compartilhar informações, regularmente, a todas as partes interessadas sobre os progressos realizados na adoção e suporte dos Princípios. Ou seja, comunicar-se publicamente, que é o melhor modo de garantir a credibilidade da iniciativa, por intermédio do banco de dados do Relatório Sharing Information on Progress (SIP), elemento facilitador quando se trata da troca de informações entre a rede PRME.

\section{Gestão de Pessoas e Educação Sustentável}

A Responsabilidade Social e Ambiental, além da ideia de sustentabilidade, influencia as organizações que têm seu ambiente marcado por privatizações, fusões e aquisições. Nesse sentido, lida com a disputa entre trabalhadores de diferentes países, adaptando-se a políticas e regras, buscando uma disposição entre vida pessoal e profissional, considerando o indivíduo responsável e cidadão (VELOSO, 2009).

Queiroz/Albuquerque (2009) e Donaire (2011) ressaltam que a globalização da economia, a internacionalização dos padrões de qualidade ambiental, a conscientização dos consumidores e a disseminação da educação sustentável nas escolas são alguns dos fatores que geram impactos significativos sobre a gestão das organizações e que possibilitam prever que a exigência futura em relação à sustentabilidade e à qualidade de vida deverá se intensificar.

A busca pela harmonia com o ambiente sustentável deve estar enfatizada não só na estratégia geral das organizações, mas também em suas práticas de Gestão de Pessoas, por meio de seu alinhamento (QUEIROZ; ALBUQUERQUE, 2009).

Pesquisas que integram a Gestão de Pessoas e a Gestão Ambiental nas organizações se apresentam insuficientes aos pesquisadores e gestores organizacionais, embora a dedicação da área de recursos humanos seja considerada fundamental para a consecução de uma administração ambiental proativa. (GOVINDARAJULU; DAILY, 2004).

$\mathrm{Na}$ esfera organizacional, essa realidade não é diferente, pois, segundo Backer (2002, p.25) "neste campo da integração das práticas de gestão de pessoas e ambiental existe uma 
dificuldade em criar uma estratégia". Nesta abordagem, Boudreau e Ramstad (2005) reiteram que os princípios de sustentabilidade raramente são explícitos nos planos estratégicos de recursos humanos, e suas implicações para a Gestão de Pessoas tem, por vezes, recebido atenção insuficiente.

À medida que as organizações incorporarem a dimensão ambiental em suas ações, caberá à área de recursos humanos provocar essa interiorização. E, de acordo com Govindarajulu e Daily (2004), a gestão ambiental é um processo complexo que requer o apoio de estratégias de recursos humanos, suscetíveis de assegurar que tal proposta alcance êxito, incorporando ao ambiente organizacional novos modelos de gestão, a fim de assegurar certo nível de competitividade atual e futuramente.

Percebe-se, nessa proposição, a ênfase nas pessoas como recurso determinante na busca pela competitividade das empresas e a necessidade de contar com profissionais altamente capacitados, aptos a fazer frente às ameaças e oportunidades do mercado. Esses profissionais devem se revelar pelo conjunto de competências que têm e que se alinham às competências inerentes à empresa.

Nesse sentido, entende-se por gestão de competências um conjunto de ferramentas que, reunidas, formam uma metodologia de apoio à Gestão de Pessoas (GRAMIGMA, 2007).

Lopes (2004) ressalta que essa gestão toma como referência a estratégia da organização e direciona suas ações de recrutamento, seleção e desenvolvimento para a captação das competências necessárias para atingir seus objetivos.

\section{Recrutamento e Seleção por competências}

Bohlander e Snell (2009) definem recrutamento como a atividade organizacional que objetiva localizar e incentivar candidatos potenciais a disputarem vagas existentes ou previstas. Portanto, o recrutamento almeja influenciar a quantidade e a tipologia dos candidatos à determinada vaga.

Quando essa atividade agrega a dimensão ambiental, o desempenho ambiental sustentável da empresa passa a ser utilizado como elemento de atração de talentos. Como visto na tabela 1, a Europa Ocidental é a que mais implementou o PRME, desenvolvendo as capacidades dos estudantes para serem futuros geradores do valor sustentável para as empresas que aderiram a essa prática. As organizações de origem alemã, por exemplo, costumam utilizar sua imagem institucional para atrair esse tipo de estudante competente e comprometido com o meio ambiente (WEHRMEYER, 1996).

Enquanto que o processo de recrutamento objetiva aumentar a quantidade de candidatos, a seleção visa à redução desse número, por meio da escolha do candidato que melhor atenda aos critérios da vaga oferecida (MILKOVICH e BOUDREAU, 2000).

No entanto, para se alcançar a integração estratégica entre a Gestão de Pessoas e os negócios da empresa, é preciso que cada atividade de recursos humanos seja interligada, de modo a se alinhar às estratégias da empresa. É relevante que a empresa possa contar com pessoas que apresentem um conjunto de competências que se alinhem às competências essenciais, especialmente às questões de mudanças ambientais, que é uma das principais fontes de vantagem competitiva (CESAR; CODA; GARCIA, 2006).

David McClelland (1973, apud Munck, 2002) apresentou a expressão 'competência' em seu artigo Testing Competence Rather for Inteligence, publicado no jornal American Psychologst. Ele admitia que a relação entre os resultados dos testes de inteligência e o respectivo sucesso profissional dos indivíduos precisava ser revista. Segundo ele, as elites não poderiam mais decidir que as habilidades dominantes estavam presentes em uma realidade social distante daquela dos menos favorecidos. Assim, construiu um conceito de competência baseado 
em três dimensões: conhecimentos, habilidades e atitudes, englobando não só questões técnicas, mas também a cognição e as atitudes relacionadas ao trabalho e à consecução de determinado propósito, de acordo com a Figura-1.

Figura 1- As três dimensões da competência

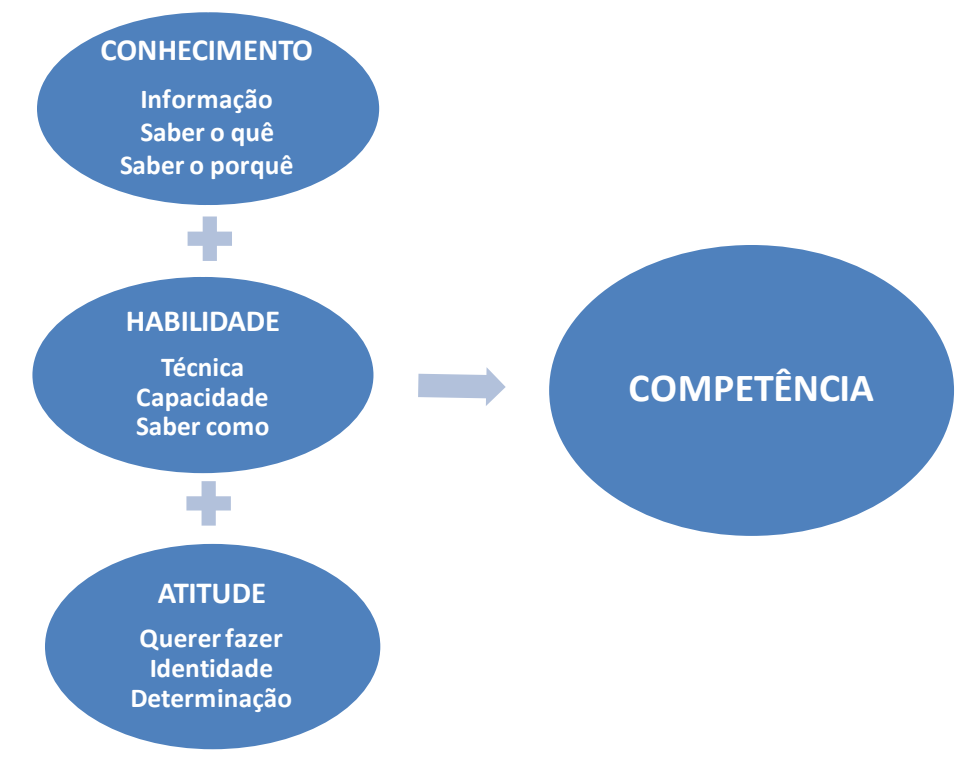

Fonte: Elaborado pelos autores (2013)

Tais dimensões são interdependentes na medida em que, para a exposição de uma habilidade, presume-se que o indivíduo conheça princípios e técnicas específicos.

Da mesma forma, a adoção de um comportamento no trabalho exige da pessoa, não raras vezes, a detenção não apenas de conhecimentos, mas também de habilidades e atitudes apropriadas (DURAND, 2000).

Assim, a prática de seleção pode contribuir com funcionários mais comprometidos com a questão ambiental e que tenham um potencial de seleção superior àqueles que não demonstram capacidade para liderar a gestão ambiental na empresa. Em algumas empresas do Reino Unido, por exemplo, as responsabilidades ambientais foram introduzidas em todas as descrições de cargo, definindo, pois, o meio ambiente como critério de seleção de novos funcionários (WEHRMEYER, 1996).

As competências requerem modelos de avaliação capazes de visualizar a manutenção e o desenvolvimento dos desempenhos funcionais sob diferentes normas e ambientes. Assim, as regras de trabalho instigam um intenso comportamento de sociabilização dos indivíduos, o que gera melhor comunicação, consequência do uso de uma linguagem organizacional comum, promotora de melhores desempenhos empresariais e individuais, além de critérios mais legítimos no recrutamento, seleção e retenção de talentos. (MARKUS; COOPERTHOMAS, ALLPRESS, 2005).

Boyatzis (2002), baseado nas proposições de McClelland (1973), desenvolveu uma série de estudos cujos resultados indicaram que, para uma eficaz gestão de competências, os critérios de avaliação teriam de ser entendidos em plenitude e mensuráveis em extensão. Nesse contexto, as concepções sobre o significado do indivíduo para a organização, bem como a retórica, são essenciais, pois, com base em sua compreensão estrutura-se um novo paradigma interessado em validar um comportamento gerencial competente. 


\section{PUC-SP}

O mesmo autor propôs um modelo de compreensão alicerçado em três premissas: as funções e responsabilidades do cargo, que revelam primeiramente o que se espera da pessoa contratada ou designada para alguma ocupação; o ambiente organizacional, que envolve alguns aspectos indispensáveis em alguém que ocupa um cargo gerencial; e as competências individuais, refletoras da capacidade individual de responder a diferentes adversidades em cenários diversos, de acordo com a Figura-2.

Figura 2 - Modelo de Compreensão de Boyatzis (2002)

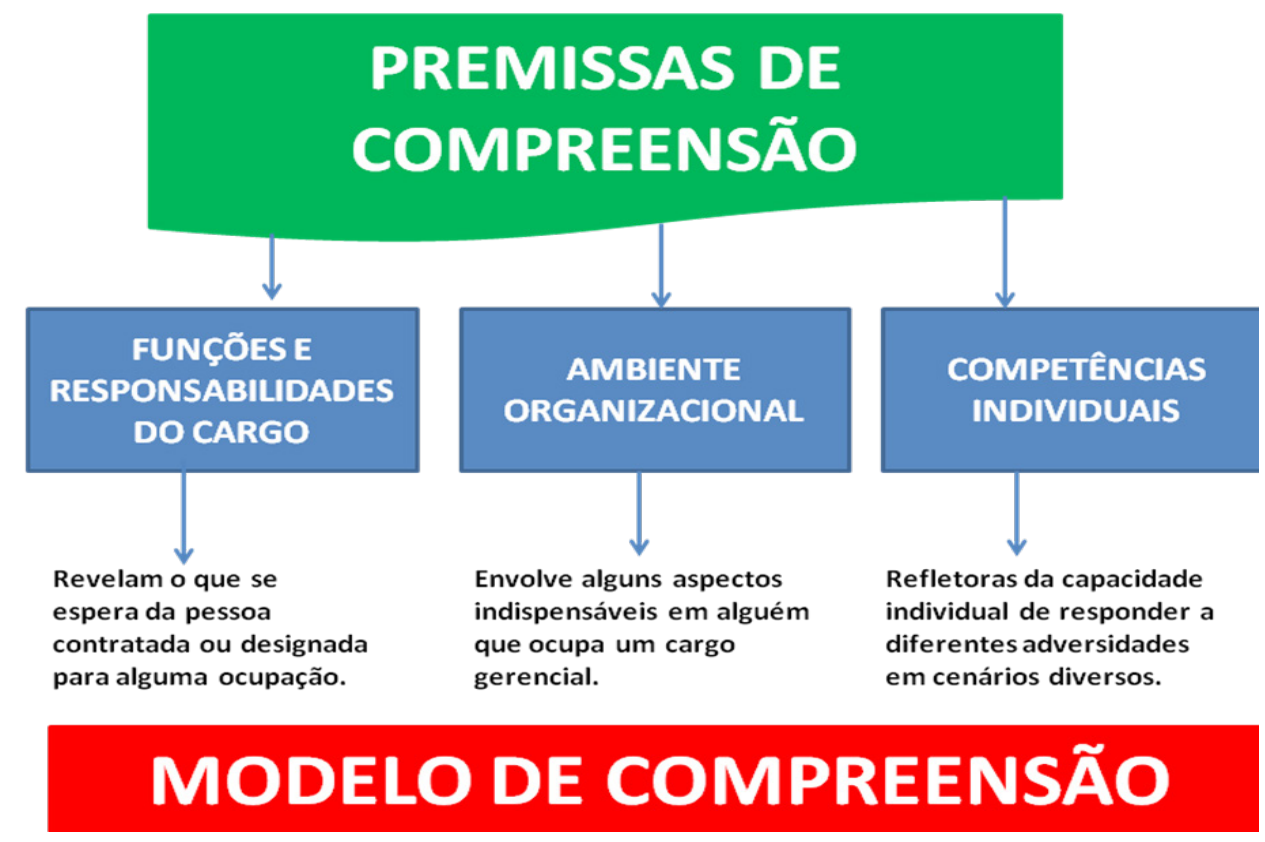

Fonte: Elaborado pelos autores baseado em Boyatzis (2002)

Importa acrescentar que a preocupação ambiental tem recebido destaque entre as diversas exigências da sociedade moderna, as quais afetam as organizações, passando a fazer parte de um quadro de ameaças e oportunidades cujas consequências podem representar posições na competitividade (DONAIRE, 2011).

Esta situação requer um desdobramento importante na gestão estratégica de recursos humanos: a de reconhecer a importância, para a empresa, da manutenção de programas de desenvolvimento profissional.

No sentido de minimizar os efeitos dessas ameaças seria interessante que a área de Gestão de Pessoas incorporasse práticas de gerenciamento calcadas nos parâmetros do desenvolvimento sustentável, prestando, assim, um papel significativo na informação e formação dos recursos humanos ao viabilizar a aprendizagem, de forma a preparar funcionários para trabalharem na perspectiva da Educação Sustentável.

Dutra (2004) destaca que um sistema de Gestão de Pessoas integrado e estratégico gera maior sinergia entre suas partes e faz com que vários processos de gestão do sistema se reforcem mutuamente, o que lhes garante maior efetividade, coerência e consistência.

A responsabilidade compartilhada entre indivíduos torna-se um objetivo essencial para promover um novo tipo de desenvolvimento - o desenvolvimento sustentável (DAHER, 2009). Nesse sentido. Rhinow (2001) realça que as pessoas aparecem como fator de alta relevância para a competitividade e sustentabilidade. 
Neste cenário, a educação torna-se um patrimônio estratégico e uma ferramenta necessária ao desenvolvimento do país, e que deve ser ajustada de forma a atingir sua configuração ideal, servindo sua função e realizando seu valor (IOSCHPE, 2004).

Segundo Pereira e Franco (2013), a adesão da universidade em prover a sustentabilidade relaciona-se à sua missão fundamental que é formar profissionais cidadãos para atuarem no mercado de trabalho, oferecendo a qualidade de um ensino para os jovens, em várias áreas do conhecimento.

Entretanto Dutra (2004) pressupõe a possibilidade da gestão por competência, permitindo seu planejamento e gestão, desde que identificadas as competências do indivíduo e da atividade. Para tanto, é necessário considerar a indicação da empresa quanto às competências que devem ser desenvolvidas e que nível de domínio e entrega são necessários para a ocupação desta ou daquela posição.

Percebe-se que, no conceito apresentado por Dutra (2004), a entrega é analisada pela sua agregação de valor à organização que, consequentemente, avalia o potencial do empregado para lidar em níveis de maior complexidade. Assim, o sucesso na carreira estaria condicionado pela capacidade daquele empregado em atender ao modelo de negócios e à estrutura organizacional de seu empregador. Legge (2005) corrobora tal ideia, ao ressaltar que a gestão estratégica de pessoas consiste em olhar internamente, reconhecendo aqueles recursos que geram valor, preferencialmente raros, inimitáveis, não substituídos e apropriados, dentre os quais aqueles empregados considerados diferenciados ou que se mostrem talentosos.

Assim, a partir do momento em que as IES introduzirem a educação sustentável em seus programas de ensino, os profissionais vão cada vez mais se qualificar. $\mathrm{E}$, à medida que isso acontecer, vão procurar organizações capazes de não apenas oportunizar novos desafios, bom ambiente de trabalho, chances de desenvolvimento e plano de carreira, mas também vão verificar se as organizações priorizam os valores e o comportamento social ético que comprovam suas convicções (TACHIZAWA, 2004).

Todavia, a construção da carreira depende em certo grau da iniciativa do trabalhador; as organizações, porém, têm um papel importante em prover recursos para que a carreira se desenvolva (DUTRA; VELOZO; FISCHER E NAKATA, 2009).

E, de acordo com Donaire (2011), o desempenho de uma organização está ativamente associado à qualidade de seus recursos humanos e deve desenvolvê-los com um programa de conscientização sustentável, alterando o comportamento das pessoas que a integram.

\section{Metodologia}

A pesquisa caracteriza-se como exploratório-descritiva, visto que se pretende verificar se as IES que utilizam os Princípios de Educação Responsável em Gestão - PRME estão conseguindo despertar nas empresas brasileiras o interesse no recrutamento e seleção de alunos que detenham conhecimento em sustentabilidade. Para tanto, os pesquisadores optaram por uma apresentação dos resultados que expusesse os aspectos citados, separandoos por assunto, a fim de facilitar o entendimento dos dados para o leitor. A seguir, comparouse com o modelo de compreensão de Boyatzis (2002), a fim de identificar as semelhanças e eventuais diferenças.

Para a coleta de dados, optou-se pela entrevista semiestruturada, uma vez que este tipo de entrevista possibilita que o entrevistado tenha liberdade de expressar sua opinião sobre o fenômeno estudado (GIL, 2010).

A população inicialmente pretendida para a entrevista foram 11 gestores de $\mathrm{RH}$, mas obteve-se o aceite de cinco deles. A coleta de dados ocorreu em janeiro de 2013. 


\section{Definição da amostra da pesquisa}

No mundo, existem 367 IES que compartilham as informações por meio dos Relatórios SHARING INFORMATION ON PROGRESS (SIP). Embora no Brasil haja 20 instituições que se reportam ao PRME, a amostra intencional desta pesquisa compreende $5 \mathrm{IES}$, por serem adesões antigas, que publicam (base 2011) o Relatório SIP - que traduz num conjunto de boas práticas e facilita a troca de informações entre a rede PRME.

Os dados para o estudo foram coletados em 5 IES, sendo uma no Estado de Minas Gerais, duas no Estado do Paraná e duas no Estado de São Paulo.

As empresas escolhidas para a entrevista pelo critério de acessibilidade são aquelas que tiveram experiências de recrutamento e seleção nas IES filiadas ao PRME. As entrevistas foram respondidas por Gestores de Recursos Humanos das empresas dos seguintes segmentos: (1) Bebidas; (2) Química e Petroquímica; (3) Auditoria e Consultoria; (4) Consultoria em Recursos Humanos; (5) Tintas e Revestimentos.

\section{Técnica para coleta e análise de resultados}

As entrevistas foram realizadas com os Gestores de Recursos Humanos das empresas. Em seguida, procedeu-se à coleta dos dados, a fim de buscar uma conexão entre as IES que preparam os futuros gestores e as empresas que os contratam, formulando-se quatro perguntas, a saber: (1) até que ponto no processo de recrutamento e seleção a empresa leva em consideração os esforços das IES em relação à educação sustentável?; (2) como as empresas mensuram os conhecimentos desses alunos?; (3) a empresa conhece os princípios da educação sustentável constantes no PRME?; (4) as IES que focam no PRME levam vantagens em relação às outras que não apresentam este princípio na hora do recrutamento e seleção?

\section{Apresentação e Análise dos Resultados}

Com base nas questões norteadoras da pesquisa pode-se identificar que as IES que seguem os princípios preconizados pela rede PRME introduziram no currículo de aprendizado do aluno os conhecimentos sobre educação sustentável, postura que provavelmente venha a enriquecer a carreira dos jovens e que poderá contribuir com o melhor desempenho destes nos processos seletivos. Porém, a maioria das empresas ainda desconhece o esforço que as IES filiadas estão realizando e não utiliza este fator nos processos de recrutamento e seleção, por causa do desconhecimento em relação ao esforço que as IES vêm realizando junto à rede PRME, no sentido de preparar melhor o aluno para o tema da sustentabilidade.

Do lado das empresas há a alegação de que as IES não divulgam que tenham filiação à rede PRME e que estejam modificando a grade curricular de ensino, razão pela qual o gestor B sugere uma ampla divulgação do tema, devido ao valor que agrega à sociedade:

GESTOR B: "As IES não informam a empresa sobre a importância do tema. Deveríamos ter mais informações, em decorrência do seu valor e ao fato relevante de a empresa possuir internamente um departamento de sustentabilidade que atende a diversas empresas no que se refere à Consultoria e elaboração do Global Reporting Initiative-GRI ${ }^{1}$. O processo de contratação é diferenciado por recrutar os talentos diretamente nas IES, onde participamos com palestras, feiras e exposições. A nossa área de RH está em contato constante com as principais IES de São Paulo e somos demandados para palestras diversas ao longo do ano"

Esta consideração apresentada pelo gestor B indica que os princípios do PRME ainda necessitam de melhor entendimento e divulgação nas empresas, o que demonstra não existirem posições contrárias para essa aproximação.

\footnotetext{
1 Global Reporting Initiative-GRI: relatório de sustentabilidade baseado nas Diretrizes da GRI divulga os resultados obtidos dentro do período relatado, no contexto dos compromissos, da estratégia e da forma de gestão da organização.
} 
Constatou-se, ainda, que os profissionais de recrutamento e seleção pouco exploram os conhecimentos de sustentabilidade apresentados pelos candidatos, evidenciando que, embora considerem importante esse domínio, não exploram suficientemente o assunto nas técnicas de seleção utilizadas. Um dos entrevistados expôs tal situação:

GESTOR A: "Hoje em dia os conhecimentos de sustentabilidade são um diferencial e cada vez mais vistos nos currículos dos jovens recém-formados".

Nas ações de educação dentro das organizações, observou-se que o tema sustentabilidade está presente, comprovando um esforço de conscientização. Apesar de as empresas pouco explorarem no processo seletivo a avaliação desse conhecimento, o gestor $\mathrm{C}$ declarou:

GESTOR C: "Não abordamos especificamente a Educação Sustentável em nossos processos seletivos, seja para o Programa de Jovens (estágios ou trainee), ou para as oportunidades efetivas".

As empresas não levam em consideração, ao efetuar o recrutamento de profissionais, se as IES possuem ou não em seus currículos a temática da sustentabilidade. Nesse sentido, o gestor E declara:

GESTOR E: "O foco principal no processo de contratação das empresas são as competências/habilidades e os requisitos buscando o alinhamento com a cultura".

Relacionando o modelo de Boyatzis (2002) com os resultados da pesquisa, percebeuse que os gestores das empresas reconhecem que a contratação de profissionais com conhecimento em sustentabilidade agrega valor à organização. No entanto, abordam apenas aspectos relacionados à cultura e pouco exploram a competência individual relacionada aos conhecimentos de sustentabilidade dos candidatos, como mostra o Quadro 3.

Quadro 3 - Comparação dos resultados com modelo Boyatzis (2012)

\begin{tabular}{|c|c|c|}
\hline \multirow{4}{*}{ = } & Modelo Boyatzis (2002) & Pesquisa (2013) \\
\hline & $\begin{array}{l}\text { As funçós e responsabilidades do cargo, que } \\
\text { revelam primeiramente o que se espera da pessoa } \\
\text { contratada ou desigmada para al guma ocupaça. }\end{array}$ & $\begin{array}{l}\text { As empresas enxergam vantagem em } \\
\text { contratar para seus quadros pesscas com o } \\
\text { conhecimento em sustentabilidade. }\end{array}$ \\
\hline & $\begin{array}{l}\text { o ambiente organizacional, que envolve alsuns } \\
\text { spectos indspensáveis em alguém que ocupa um } \\
\text { cargo gerendal, }\end{array}$ & $\begin{array}{l}\text { O foco principal no processo de contrataçòo } \\
\text { das empresas são as competêndiashabilidades } \\
\text { e os requisitos busc ando o alinhamento com a } \\
\text { cultura. }\end{array}$ \\
\hline & $\begin{array}{l}\text { As competêndias individuais, refletoras da } \\
\text { capacidade individual de responder a diferentes } \\
\text { adver sidades em cenários diversos. }\end{array}$ & $\begin{array}{l}\text { O recrutamento e seleçä́o das empresas pouco } \\
\text { exploram os conhecimentos de } \\
\text { sustentabilida de trazidos pelos candidatos. }\end{array}$ \\
\hline
\end{tabular}

Fonte: Dados da Pesquisa (2013).

Por conseguinte, sabendo o que esperar desse contexto, selecionar profissionais mais adequados, um programa de recrutamento e seleção com quesitos de avaliação da sustentabilidade e, principalmente, um desenvolvimento de carreira poderão se constituir em um modelo que aumente a integração das duas partes envolvidas: a IES e a Empresa. 


\section{Considerações Finais}

Mundialmente, a educação superior e a do Brasil, em especial, têm passado por reflexões, inovações e mudanças. Assim, as implementações requeridas devem ser executadas, considerando-se que a sociedade contemporânea lida com ambientes diversificados e complexos. A importância das IES nesse contexto é fundamental, razão pela qual há expressiva preocupação com o tipo de formação promovida pelos gestores, tendo em vista o papel que desempenham na tomada de decisão das mais diversas organizações.

Todavia, a análise dos relatórios PRME indica que parte das IES brasileiras mostra certo desconhecimento aos PRME, exceção feita às $20 \mathrm{IES}^{2}$, que estão inseridas na adoção dos princípios no mundo, das quais $11 \%$ se localizam na America Latina, conforme Tabela-1. E, sob essa perspectiva, os alunos que frequentaram as IES que contemplam esses princípios não se tornam candidatos potenciais nos processos de recrutamento e seleção em empresas brasileiras, pois elas não os priorizam..

Cumpre ressaltar, ainda, que esta pesquisa se distinguiu por identificar que os Relatórios SIP não são unificados e que não existe um padrão para publicação. Também os PRME são recentes, uma vez que foram desenvolvidos em 2007, passíveis, pois, de consistência plena em seus relatos.

Por conseguinte, embora princípios como ética, sustentabilidade e responsabilidade social não sejam novidade, sua adoção de forma planejada e sistemática nas ações educativas para o aprimoramento do ensino é a valiosa contribuição desta pesquisa às empresas e às IES.

Conclui-se desse contexto que os candidatos mais bem preparados nos quesitos de sustentabilidade podem estar sendo prejudicados no desenvolvimento de suas carreiras e, principalmente, enquanto não ocorrer a integração das duas partes envolvidas: a IES e a Empresa.

2 (1) Associação Nacional dos Cursos de Graduação em Administração; (2) Brazilian School of Public and Business Administration-EBAPE; (3) Universidade Anhembi Morumbi; (4) Escola de Administração de Empresas de São Paulo - EAESP; (5) Escola Superior de Propaganda e Marketing-ESPM; (6) Estação Business School; (7) Faculdades Integradas Santa Cruz; (8) FEA-RP USP; (9) Federal University of Paraná; (10) FIA-Fundação Instituto de Administração; (11) Fundação Dom Cabral -FDC; (12) IAG - Business School; (13) IBPEX; (14) Instituto de Tecnologia do Paraná-TECPAR; (15) ISAE/FGV; (16) National Service of Industrial Apprentice of Paraná - SENAI; (17) Social Service of Industry-SESI; (18) Sociedade Latino Americana de Coaching; (19) Universidade Positivo; (20) Universidade Tecnológica Federal do Paraná UTFPR. 


\section{Referências Bibliográficas}

ALBUQUERQUE, L. G.; LEITE, N. P. (Org.) Gestão de Pessoas-Perspectivas estratégicas. São Paulo: Atlas, 2009.

BACKER, P. Gestão ambiental: a administração verde. Rio de Janeiro: Qualitymark, 2002.

BARBOSA, A.M. (Org.). Inquietações e mudanças no ensino da arte. São Paulo: Cortez, 2002.

BOFF, L. Sustentabilidade - O que é - O que não é. Petrópolis, RJ: Vozes, 2012.

BOHLANDER, G.; SNELL, S. Administração de Recursos Humanos. São Paulo: Cengage Learning, 2009.

BOUDREAW, J. W.; RAMSTAD, P.M. Talentship, talent segmentation and sustainability: a new HR decision science paradigm for a new strategy definition. Human Resource Management, v.44, n.2, p.129-136, 2005.

BOYATZIS, R. E., GOLEMAN, D. \& RHEE, K. S. Clustering competence in emotional intelligence, 2002 in BAR-ON, R. \& PARKER, J. D. A. Manual de Inteligência Emocional. Ed. Artmed, Porto Alegre, 2002.

CESAR, A. M. R. V.; CODA, R.; GARCIA, M. N. Um novo RH? Avaliando a atuação e o papel da área de RH em organizações brasileiras. FACEF Pesquisa, v.9, n.2, 2006.

DAHER, W. M. Responsabilidade Social Corporativa. Geração de valor reputacional nas organizações internacionalizadas. São Paulo: Saint Paul, 2009.

DEA JUNIOR, J. G.; ROSA, I. M.; SAMPAIO, C. P. Diretrizes Ambientais para um Campus sustentável Avaliadas pela ótica do Design. Projetica, Londrina, v. 1, n.1, p. 162-183, dez. 2010.

DIAS, L.F. Apóstila de Estatística. Porto Alegre: UFSM, 2003.

DONAIRE, D. Gestão ambiental na empresa. São Paulo: Atlas, 2011.

DURAND, T. L. Alchimie de la compétence. Revue Française de Gestion, n. 127, p. 84102, jan./fev., 2000.

DUTRA, J. S. Competências: conceitos e instrumentos para a gestão de pessoas na empresa moderna. São Paulo: Atlas, 2004.

DUTRA, J. S. ; VELOZO, E. F. R. ; FISCHER, A. L. ; NAKATA, L. E. As carreiras inteligentes e sua percepção pelo clima organização. Revista brasileira de orientação profissional, v.10, n. 1. São Paulo, jun. 2009.

FLYNN, B.B.; KAKIBARA, S.S.; SCHROEDER, R.G.; BATES, K.A.; FLYNN, E.J. Empirical Research Methods in Operations Management. Journal of Operations Management. Vol.9, No 2. April 1990.

GADOTTI, M. Educar para a sustentabilidade. Inclusão social, Brasília, v.3, n.1, p. 75-78, out.2007/mar. 2008.

GIL, A.C. Gestão de Pessoas. Enfoque nos papéis profissionais. São Paulo: Atlas, 2010.

GIL, A. C. Métodos e técnicas em pesquisa social. 5 ed. São Paulo: Atlas, 1999.

GOVINDARAJULU,N.; DAILY, B. F. Motivating employees for environmental improvement. Industrial management \& Data Systems, v. 104, n. 4, p. 364-372, 2004.

GRAMIGNA, M. R. Modelo de competências e gestão de talentos. São Paulo: Pearson, 2007.

IOSCHPE, G. A ignorância custa um mundo; o valor da educação no desenvolvimento do Brasil. São Paulo: Francis, 2004.

LEGGE, K. Human Resource Management: Rhetorics and Realities. Basingstoke: Macmillan, 2009. 
LEITE, N. P.; PAROLIN, S. R. H.; BOSQUETTI, M. A.; SILVA, L. M. T.; BIANCHI, E. M. P. G. Treinamento, desenvolvimento e educação de pessoas: desafio na estratégia organizacional. In: ALBUQUERQUE, L. G.; LEITE, N. P. (Org.) Gestão de Pessoas - Perspectivas estratégicas. São Paulo: Atlas, 2009.

LOPES, C. P. C. Gestão por competência como ferramenta para um RH estratégico. Monografia em administração. Universidade Católica de Pernambuco, 2007.

MACCLELLAND, D. Testing for competence rather than for "intelligence". American Psychologist, v. 28, n.1, p.1-14, 1973.

MARKUS,L.H.; COOPER-THOMAS, H.D.; ALLPRESS, K.N. Confounded by Competencies? An evaluation of the evolution and use of competency models. New Zealand Journal of Psychology, v.34. n.2, p.117-126, 2005.

MILKOVICH, G. T.; BOUDREAU, J. W. Administração de Recursos Humanos. São Paulo: Atlas, 2000.

MILLMORE, M. Just how expensive is the practice of strategic recruitment and selection? Irish Journal of management. Bradford, v. 16, n.3, p. 287-309, 2003.

NAVARRO, R. Conversas com os mestres da sustentabiidade. São Paulo: Gente, 2009

ONU - ORGANIZAÇÃO DAS NAÇÕES UNIDAS. Além da Rio +20: Avançando rumo a um futuro sustentável. 29 ago. 2012. Disponível em < http://www.onu.org.br/rio20/tema/ desenvolvimento-sustentavel/>. Acesso em 16 nov. 2012.

PEREIRA, R. S. Desenvolvimento sustentável como responsabilidade social nas empresas. In: PEREIRA, R. S. (Org.) Gestão para o desenvolvimento sustentável: desafios e proposições para a sustentabilidade socioambiental. São Paulo: Globus, 2013.

PETTIGREW, A. ; SARROW, P.; HENDRY, C. The forces that trigger training. Personnel Management, v. 20, n.12, 2008.

PRME - PRINCIPLES FOR RESPONSIBLE MANAGEMENT EDUCATION. Contexto e Princípios. 29 ago. 2012. Disponível em:<4 http://www.unprme.org/index.php> Acesso em 14 nov. 2013.

QUEIROZ, A. C. S.; ALBUQUERQUE, L. G. Análise do ambiente organizacional. In:

RHINOW, G. Inovando e competindo por meio da gestão de pessoas. RAE Light - Revista de Administração de Empresas, São Paulo, v.8, n.1, p. 2-7, jan./mar. 2001.

ROEDEL, D. A sustentabilidade como requisito para a gestão competitiva. Revista Plurimus, Rio de Janeiro, ano 1, jan/jun.2012.

SACHS, I. Desenvolvimento sustentável. Brasília: IBAMA - Instituto Brasileiro do Meio Ambiente e dos Recursos Renováveis, 1996.

SAMPIERI, R.H., COLLADO C.F.; LUCIO, P.B. Metodología de La Investigación. México: McGraw Hill, 2003.

SANA, J. J. B. Práticas e saberes de pedagogas e pedagogas: a formação humana em questão. Vitória: Flor\& Cultura, 2006.

SILVA, J, U. A educação como agente transformador: o capital intelectual como diferencial no mercado de trabalho. In: GUEVARA, A. J. H.; ROSINI, A. M. R.; SILVA, J. U.; CALADO. L. R.; RODRIGUES, M. C. (Org.) Educação para a Era da Sustentabilidade. São Paulo: Saint Paul, 2011.

SILVA, J, U. A educação no Vale do Jequitinhonha. São Paulo: Educ, 2009.

TACHIZAWA, T. Gestão ambiental e responsabilidade social corporativa: estratégias de 
negócios focadas na realidade brasileira. São Paulo: Atlas, 2004.

UNESCO - ORGANIZAÇÃO DAS NAÇÕES UNIDAS PARA A EDUCAÇÃO, A CIÊNCIA E A CULTURA. Lançada a Iniciativa de Educação Superior para a Sustentabilidade na Rio+20. Brasília, 21 jun. 2012. Disponível em:<http://www.unesco.org/new/pt/rio-20>. Acesso em 15 nov. 2012.

VEIGA, J. E. Desenvolvimento sustentável: o desafio do século XXI. Rio de Janeiro: Garamond, 2006.

VELOSO, E.F.R. Carreiras sem Fronteiras na Gestão Pessoal da Transição Profissional. Tese de Doutorado. Universidade de São Paulo, 2009.

WANDERLEY, L. E. O que é universidade. São Paulo: Brasiliense, 1983.

WEHRMEYER, W. Green policies can help to bear fruit. People Management,v.2, p. 3840, 1996. 